\title{
MIT: A Way from Singing to Speaking in Patients with Non-Fluent Aphasia
}

\author{
Govathi Nikhila K$^{*}$ \\ Speech Therapist, Medanta -The Medicity Hospital, India
}

Submission: August 23, 2018; Published: September 04, 2018

*Corresponding author: Govathi Nikhila K, Speech Therapist, Medanta -The Medicity Hospital, Gurgaon, Haryana, India, Email: gnikhilaks@gmail.com

\section{Abstract}

In 1973 , music-based treatment [Melodic Intonation Therapy (MIT)] was developed. For more than 200 years, clinicians have noted that patients with nonaffluent aphasia are capable of singing words that they cannot speak. Thus, the use of melody and rhythm has long been recommended for improving aphasic patients. (MIT) is one of the most formalized treatments used by speech-language therapist in Broca's aphasia. We suggest basic clarifications to enhance the scientific support of this promising treatment. First, therapeutic protocols using singing as a speech facilitation technique are not necessarily MIT. The goal of MIT is to restore propositional speech.

\section{Introduction}

Melodic Intonation Therapy [1,2]. is a treatment program used by speech-language pathologists for the rehabilitation of patients with speech production disorders? At the first levels of the MIT program, musical components are used to facilitate verbal expression. Typically, the clinician asks the patient to produce everyday sentences in a singing-like manner that exaggerates the natural prosody (pitch variation and rhythmic features) while tapping with the left hand on each syllable. MIT was initially based on the hypothesis that music processing regions of the right cerebral hemisphere had language capabilities, and that they could potentially compensate for damaged left hemisphere language regions. The participation of the left hand was thought to help the intoned-speech facilitation technique stimulate language-capable areas in the right hemisphere.

The American Academy of Neurology has rated the MIT as promising for brain-damaged patients who meet the criteria for Broca's aphasia (AAN, 1994). Because MIT is one of the most formalized treatments in speech-language therapy (AAN, 1994), it is particularly well suited for scientific study. However, 40 years after its original publication, systematic reviews still comment on the low quality of the MIT efficacy studies and raise questions regarding the treatment mechanisms $[3,4]$. In fact, in addition to intoned speech, MIT includes various other therapeutic techniques (e.g., rhythmic speech, auditory and visual cueing, production of formulaic expressions) that make the study of MIT's mechanisms challenging.

\section{Singing Along Rather than Singing Alone}

One of the most compelling reasons for using singing in a speech facilitation technique in MIT (Albert et al., 1973) is that patients with severe non-fluent aphasia were clinically described to produce words in familiar songs although they had otherwise extremely reduced speech output (Gerstman, 1964; Symonds, 1953). Further reports (Jacome, 1984; Keith \& Aronson, 1975; Yamadori et al., 1977) gave rise to the general idea that singing would provide an effective way for people with aphasia to pronounce words. More recently, however, controlled quantitative studies have questioned this idea, having failed to demonstrate the superiority of the singing condition over normal speech for word production in non-fluent aphasia (Cohen \& Ford, 1995 [12 subjects]; Hébert, Racette, Gagnon, \& Peretz, 2003 [1 subject]; Peretz, Gagnon, Hébert, \& Macoir, 2004 [1-subject]; Stahl, Kotz, Henseler, Turner, \& Geyer, 2011 [17 subjects]). It was hypothesized that the automatic status of lyrics in over-learned songs could account for the earlier clinical descriptions of better verbal production in familiar songs compared to spontaneous speech.

\section{What is MIT and How does it Used}

MIT was developed to improve propositional language $[1,2]$. or the generative and controlled language production that people use in everyday life to express their ideas (Jackson, 1878). Propositional language requires an assemblage of structures according to a set of phonological, morphological, and grammatical rules and in accord with a lexicon. It is opposed to non-propositional language (also referred to as automatic, or formulaic language), which is also used in everyday life, but which consists of a repertory of readymade and over-learned expressions (for example, idioms, proverbs, and even longer material in prayers or in songs; see Van Lancker Sidtis, 2006 for a review). This type of non-generative verbalization is known 
to be relatively preserved in Broca's aphasia (Van Lancker Sidtis, 2006).The original program of music intonation therapy is designed to lead nonfluent aphasic patients from intoning (singing) simple, 2-3 syllable phrases, to speaking phrases of 5 or more syllables across three levels of treatment $[5,6]$.

Each level consists of 20 high-probability words (e.g., "water") or social phrases (e.g., "I want water") presented with visual cues. Phrases are intoned on just two pitches, "melodies" are determined by the phrases' natural prosody [e.g., stressed syllables are sung on the higher of the 2 pitches, unaccented syllables on the lower pitch and the patient's left hand is tapped $1 \times$ per syllable. Although it may appear that the primary difference between the levels is phrase length, the more important distinctions are the administration of the treatment and degree of support provided by the therapist.

MIT is mostly useful for patients with Aphasia and it is mostly recommended and useful for patients with following characteristics:

a. A Unilateral, Left -hemisphere stroke.

b. Poorly articulated, non-fluent/severely restricted speech output.

c. Ability to produce some intelligible words while singing familiar songs.

d. Poor repetition, even for single words.

e. Moderately well preserved auditory comprehension. f. Poorly articulated attempts at speech.

g. Good motivation, emotional stability, and good attention span.

\section{How Does MIT done in Initial Stage of Speech Therapy}

There are 5 sequencing steps used in speech therapy procedure to train the aphasia patient.

Humming: Firstly, therapist introduce the target phrase by showing a visual cue, humming the phrase $1 \mathrm{x}$ at a rate of 1 syllable/word, then intoning (singing)the phrase $2 x$ while tapping on the patient left hand $1 \mathrm{x}$ per syllable/word [7].

Unison Intoning: Therapist and patient intonate(sing) the target phrase together while the therapist taps on the patients left hand $1 \mathrm{x}$ syllable.

Unison Intoning with Fading: Therapist and patient begin to intone(sing) and tap the target phrases together, but half way through ,the therapist fades out while the patient continues to sing the rest of the phrase accompanied by hand-tapping, but with no further verbal or oral /facial cueing.

Immediate Repetition: Therapist intones and taps the target phrase while the patient listens. The patient immediately repeats the phrase assisted only by tapping of left hand.

Response to a Probe Question: Immediately following the patient's successful repetition of the target phrase,the therapist quickly intones a question(ex: what did you say?) and the patient answers by intoning the target phrase. Hand tapping is the only assistance allowed [8-11] (Figure 1).

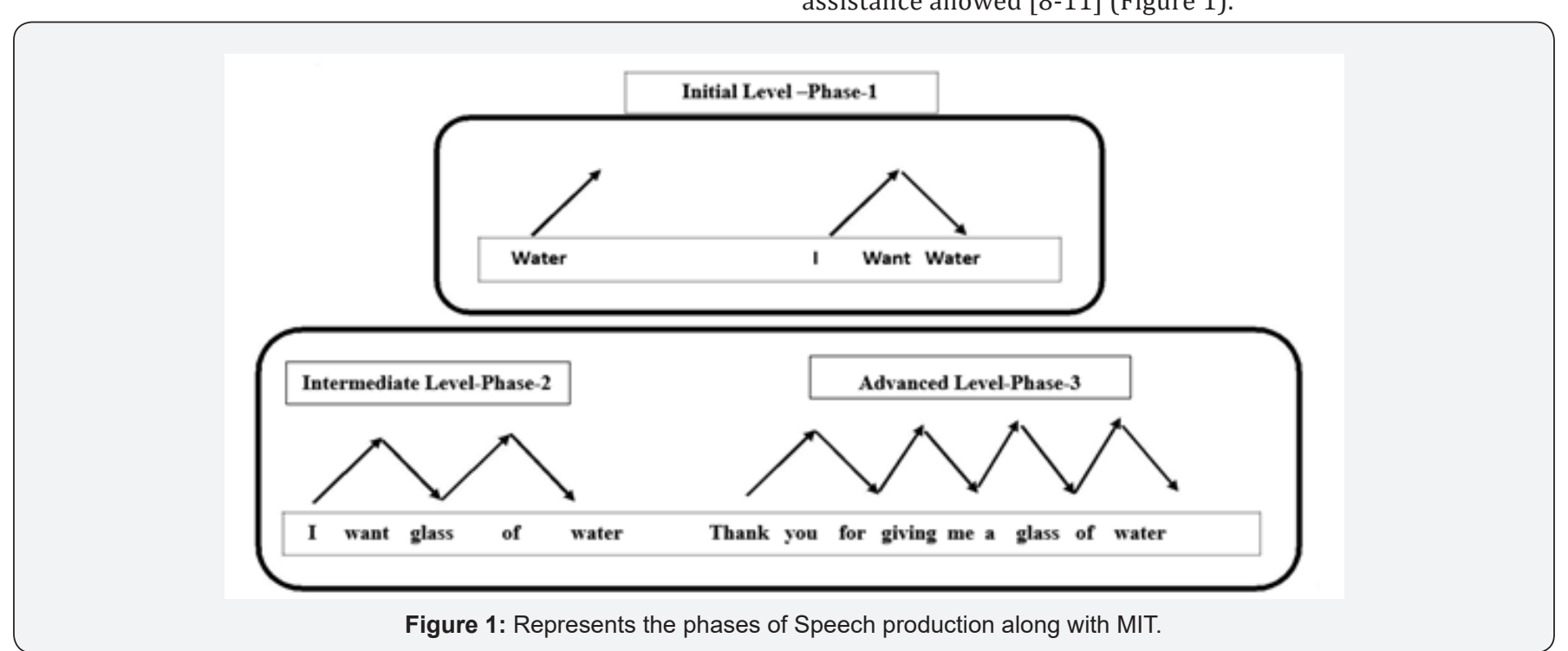

How does MIT do in Intermediate Stage of Speech Therapy

If the patient achieved targeted first initial phase, then they are moved to the Intermediate phase with 4 targeting levels in order to achieve their speech. The targeted 4 levels are as follows:
Phrase Introduction: Therapist shows a visual cue and intones the phrase $2 \mathrm{x}$, while tapping the patients left hand $1 \mathrm{x}$ syllable/word.

Unison with Fading: Therapist and patient begin to intone and tap the target phrase together, but halfway through the therapist fades out while the patient continues to sing the rest of 
the phrase accompanied by hand -tapping, but with no further verbal or oral/cueing.

Delayed Repetition: Therapist intones and taps the target phrase while the patient listens. After a 6-seconds delay, the patient repeats the phrase assisted only by the tapping of the left hand. No verbal assistance may be given.

Response to a Probe Question: Following the patient's successful repetition of the target phrase, the therapist waits 6- seconds, then quickly intones a question (ex: what did you say?) and the patient answers by intoning the target phrase. No assistance is allowed.

\section{How does MIT do in Advanced Stage of Speech therapy}

This is the final stage were the patient cross the phrase level and enters to the sentence level In this it consists of 5 stages as follows:

Delayed Repetition: Therapist intones and taps the target phrase while the patient listens. After a 6-seconds delay, the patient repeats the phrase assisted only by the tapping of the left hand. No verbal assistance may be given.

Introducing Sprechgesang: Therapist presents the target phrase in sprechgesang 2x (accompanied by hand tapping) while the patient listens. The words should not be sung, but instead, should be presented slowly with exaggerated emphasis on rhythm and stressed(accented) syllables.

Sprechgesangs With Fading: Therapist and patient begin the target phrase together (with hand tapping), but halfway through, the therapist fades out while the patient completes the phrase alone.

Delayed Spoken Repetition: Therapist presents the target phrase using normal speech prosody (no hand tapping) while the patient listens. After a 6- second delay, the patient repeats the phrase using normal speech.

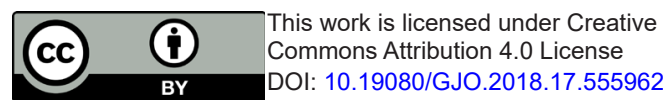

Response to a Probe Question: After a 6- second delay, the therapist asks a question to elicit the target phrase using normal speech. The patient answers by speaking the target phrase without assistance of any kind.

\section{References}

1. Albert ML, Sparks RW, Helm NA (1973) Melodic intonation therapy for aphasia. Arch Neurol 29(2): 130-131.

2. Sparks R, Helm N, Albert M (1974) Aphasia rehabilitation resulting from melodic intonation therapy. Cortex 10(4): 303-316.

3. Helm Estabrooks N, Nicholas. M, Morgan A (1989) Melodic Intonation Therapy. Pro-Ed., Inc. Austin,TX.

4. Helm Estabrooks N, Albert ML (2004) Melodic Intonation Therapy: Manual of Aphasia and Aphasia Therapy, $\left(2^{\text {nd }}\right.$ edn). Pro-Ed. Austin, TX Chapt 16, pp. 221-233.

5. Schlaug G, Marchina S, Norton A (2008) From singing to speaking: why singing may lead to recovery of expressive language function in patients with Broca's aphasia. Music Percept 25(4): 315-323.

6. Anglade C, Thiel A, Ansaldo AI (2000) The Complementary role of the cerebral hemispheres in recovery from aphasia after stroke: A critical review of literature. Brain Injury 28(2): 138-145.

7. Ballard KJ, Granier JP, Robin DA (2000) Modifying the melodic intonation therapy program for adults with severe non-fluent aphasia. Music Therapy Perspectives 18.

8. Donald Robin A, Jay Granier P, Kirrie Ballard (2000) Understanding the nature of apraxia of speech: Theory, analysis, and treatment. Aphasiology 14(10): 969-995.

9. Assessment: melodic intonation therapy Report of the Therapeutics and Technology Assessment Subcommittee of the American Academy of Neurology. Neurology 44(3 pt 1): 566-568.

10. Ackermann H, Wildgruber D, Daum I, Grodd W (1998) Does the cerebellum contribute to cognitive aspects of speech production? A functional magnetic resonance imaging (fMRI) study in humans. Neuroscience Letters 247(2-3): 187-190.

11. Hough MS (2010) Melodic Intonation Therapy and aphasia: Another variation on a theme. Aphasiology 24(6-8): 775-786,

Your next submission with Juniper Publishers will reach you the below assets

- Quality Editorial service

- Swift Peer Review

- Reprints availability

- E-prints Service

- Manuscript Podcast for convenient understanding

- Global attainment for your research

- Manuscript accessibility in different formats

( Pdf, E-pub, Full Text, Audio)

- Unceasing customer service

Track the below URL for one-step submission

https://juniperpublishers.com/online-submission.php 